\title{
THE OPTIMUM FOREST ROTATION
}

\author{
By P. H. PEARSE ${ }^{1}$
}

Oxf. $651-5$

\section{ABSTRACT}

The basic factors influencing the optimum economic rotation are analysed and explained. A simple theoretical formulation of solution of the optimum rotation is described using elementary economic concepts, and its application is demonstrated. The solution is presented in a form which facilitates examination of the effects of various economic factors - the interest rate, additional costs, and silvicultural activities — on the optimum rotation.

\section{INTRODUCTION}

Determination of the best age at which forests should be harvested is among the oldest problems in forestry. It is also one of the most important. Leading forest economists have referred to it as " . . . the most important single decision in management plans". (Chapman and Meyer 1947). Yet although the optimum rotation has been the subject of periodic investigation for over a hundred years, and in spite of the efforts of many highly competent economists, there remains little agreement on the correct answer. This is serious, because incorrect solutions to the most important economic problem affecting a resource as significant as forests are bound to be costly. (Smith and Haley 1964).

The persistence of confusion over this problem is a paradox. One of the earliest applications of capital theory was carried out by Martin Faustmann in which he investigated this very problem (Faustmann 1849). Faustmann's solution is well known in forestry literature and is essentially correct. But his contribution has been almost completely ignored by economists (even by the Austrians who devoted much study to capital theory). More surprising still, while the Faustmann formula is generally familiar to foresters, they rarely accept it. Sixty-five years ago Bernhard Fernow noted that ". . . for nearly forty years a fierce literary battle as to the propriety of applying either one or the other method (of determining the optimum rotation) has been waged ..." (Fernow 1902). But even Fernow, after a brief reference to an economically correct solution, rejects it in favour of a solution which subsumes that capital is costless. The last few decades have witnessed a proliferation of alternative criteria in the forestry literature which have not helped to remove confusion about the basic issues involved.

Recently, however, two excellent analyses of the problem have appeared which examine rigorously the economic implications of the most well-known rotation criteria (Gaffney 1960: Bently and Teeguarden 1965). These have substantially clarified the problem for sophisticated readers. We now need a simple formulation of the optimum economic solution understandable to students and managers with no more than an elementary understanding of the principles of economics.

The problem, though not inherently complicated, has been confused not only by the plethora of competing criteria but also by their often com-

${ }^{1}$ Associate Professor of Economics, Univ. of British Columbia. 
plicated presentation in the literature. But simple problems can usually be analysed in simple terms. It is the purpose of this paper to present the economically correct solution of the rotation problem using no more than the most basic concepts of economic analysis, and to show how various kinds of economic influences will affect the optimum rotation.

\section{CONTEXT OF THE ANALYsis}

At the outset, it is important to recognise that an optimum solution depends upon the objectives of the decision-maker. In North America the value of forests lies primarily in the economic value of wood produced. Exceptions can be found where the value of forests is primarily in their aesthetic or recreational benefits, in erosion or run-off control, or as shelter for wildlife. Rather more frequently, these other values overlap timber values on a given forest. But in most cases these other values tend to be of small importance relative to the value of wood production. For present purposes, therefore, it will be assumed that the objective of forest management policies, from the point of view of both the forest owner and society, is to maximize the economic value of the forest resource in terms of wood production. This is not to suggest, of course, that other benefits of the forest should not be considered where they are significant. Wherever non-wood values are involved and are not precisely complementary to wood production, the solutions demonstrated below will require some modification.

It follows that as long as the value of the forest resource lies in the economic value of wood production a forest policy that aims at maximizing any magnitude other than wood values will tend to prejudice the real contribution of the forests to society as well as to the forest owner. ${ }^{1}$

The appropriate choice among alternative management possibilities is thus taken as that which will maximize the net economic value of wood produced. As with other production problems, the solution is to be found in maximizing the net return (or rent) to the fixed factor in the production process - in this case the land.

In the following analysis, it is assumed that ecological, silvicultural and other factors render clear-cutting the optimum management regime from an economic point of view. The discussion is thus based on even-aged forests, where the rotation period is the number of years between complete harvests of all merchantable timber on a given area. The determination of the optimum age for harvesting individual trees in an uneven-aged forest does not differ in principle, but since it requires a somewhat different treatment of the variables involved the case of the "selection forest" will, for simplicity, be omitted from the present discussion.

For further simplicity, it will be assumed that no time elapses between harvest and the establishment of the next crop, wherever a succession of crops is involved. In those cases where a regeneration period should be provided for, the formulation of the optimum rotation requires an additional term, though this does not change the general form of the solution.

To facilitate concentration on the essential relationships involved in the problem, it will be assumed also that the establishment and growing of the forest crop requires no outlays, though it will be demonstrated later that it is a simple matter to provide for such costs. 
Finally, it will be assumed that wherever a succession of crops is planned, all crops will be similar in all respects, including their economic value. This permits the analysis to proceed unencumbered by provisions for uncertainty and expectations of changing variables. These must be regarded as essential considerations in practice, and can be expected to alter the results, but they involve a rather separate body of theory and will be left for a separate analysis. We shall deal here with the simplest case in an effort to clarify the underlying principles.

\section{The ECONOMIC Variables InVolved}

The first step in determining the rotation that will maximize the value of the wood-growing enterprise is to isolate all costs and revenues involved. The revenues are represented by the value of the timber produced. The value of standing timber is usually expressed as stumpage, which is the value of the timber at some utilization or transportation centre minus the costs of logging and delivery. ${ }^{2}$ It is thus the maximum price that an efficient logger in competition will be willing to pay for standing timber.

The stumpage value of a forest stand tends to increase with the age of the stand for at least three reasons. First, since trees continue to add an increment of wood each year as long as they survive, the cumulated wood volume increases until the natural loss through mortality and decay exceeds the declining net increment on the remaining trees. For most commercial timber species in the northern hemisphere, the point of culmination of stand volume occurs only after a very long period (typically several hundred years) - well beyond any rotation period that will permit an economic return under management.

Secondly, while the total volume in the stand increases as the trees become older and larger, the wood value per unit (e.g. per cubic foot) increases as well. Larger timber is worth more to utilization plants because it can be converted into more valuable products than can small timber. This results not only from the limitations imposed by the dimensions of logs, but also from the tendency for large timber to have superior technical qualities of various kinds (e.g. clearer wood).

Finally, as a general rule, relatively large timber usually costs less per unit to harvest and to handle than does small timber, within limits. Since stumpage reflects the value of the harvested timber minus harvesting costs, this fact tends to raise the stumpage value of older stands also.

The costs involved in the forest enterprise are less straightforward. For simplicity, let us assume away all taxes, managerial, administrative and other recurrent costs for the time being. We are then left with two distinct costs in growing timber: the cost (interest) involved in holding capital in the form of the timber inventory, and the cost (rent) of the land. Before quantifying these costs, it will be useful briefly to justify them since both have been the subject of considerable debate in the forest literature.

Resources have economic value only when they are scarce. The real economic cost of using a scarce resource in a particular way is the sacrifice involved in diverting it from other uses. This cost is measured by what the resource can earn in its next best use. If a resource has no alternative opportunities for employment, it has no "opportunity cost" and therefore 
society sacrifices nothing from its employment in the single available activity. But as long as a resource has alternative uses, a real social cost is involved in using it - and this cost is represented by its value in its highest alternative employment. In the absence of market imperfections, private entrepreneurs, like society as a whole, will gain most by allocating all resources to their highest use, and this will be done because they can earn higher returns in that use than in any other. Thus the implicit assumption in much of the forestry literature that certain factors are costless (such as land, or capital in the form of trees) is incompatible with the concept of opportunity cost, which is basic to the whole of economic theory.

Since capital is not unlimited, it cannot legitimately be considered free, by either private entrepreneurs or governments. There is always an alternative use of capital which will yield a return. Thus the real cost of using capital in a particular way (such as holding it in the form of a timber inventory) is the return it can earn in its highest alternative use. The return on capital to any particular use is the rate of interest that could be obtained if the user (public or private) directed it to its highest alternative use. If capital is not earning at least as much as it could earn in its next best alternative, the private investor is not maximizing his return, and, whether the investor is private or public, society as a whole suffers from the misallocation of economic resources.

The cost of holding an inventory of timber is therefore the interest charge on the value of the timber capital; and the appropriate rate of interest is the highest rate that the investor could earn (after appropriate allowance for risk and uncertainty) on capital invested elsewhere.

The meaning and function of the second cost - the cost (rent) of the land - has been much confused in forestry literature. Much of the confusion has resulted from the contention that as long as forest land is useable for no purpose other than growing trees, it has no opportunity cost: there is no sacrifice in terms of alternatives foregone, and hence it is inappropriate to apply a cost to the land. This argument is basically incorrect. A forest owner always has an alternative to holding his land under the present crop of trees, namely to cut the trees and (perhaps) begin a new crop.

The value of bare forest land is the discounted present net worth of the future crops of trees that can be grown on the land. Such a value can readily be converted to an annual rent (see below). The annual cost of holding land under the present crop of timber, therefore, is equal to the rent that would begin to accrue to the land if it was reduced to a bare condition through harvesting the present stand.

This second cost, in other words, represents the cost of postponing future harvests. It is essential to include this cost in order to take account of the value of the land in producing crops other than the present stand of timber.

The Conditions For the OPtIMUM Rotation

The relevant costs and revenues are therefore straight-forward - in principle at least. On the revenue side is the stumpage value of the timber, increasing at a rate that changes through time as the forest grows older. ${ }^{3}$ On the cost side is the interest charge on the capital tied up in the form of timber, and the opportunity cost of the land. 
The optimum period over which to grow timber is analogous to the familiar optimum level of output for a firm. As Zivnuska has suggested,

\footnotetext{
"The key to the forestry entrepreneur's action, then, is the same as that for other entrepreneurs: a comparison of anticipated production cost with anticipated sale price. Thus in overall conception the economic theory of forestry is in accord with orthodox theory". (Zivnuska 1949)
}

Elementary economics demonstrates that the firm will always maximize profit by operating at that level where the marginal cost rises to equal marginal revenue. Analogously, the optimum rotation length (level of output) is that age of the forest in which the incremental (marginal) cost rises to equal incremental (marginal) revenue.

The relevant magnitudes are illustrated in Figure 1-A. The annual incremental change in the stumpage value $(S)$ of the forest over time $(t)$ is depicted by the curve $\Delta S$. If the value per cubic foot of wood was fixed regardless of the size or age of the trees, this curve would be exactly the same shape as the foresters "current annual increment" schedule, which indicates the annual incremental change in total volume of the forest over time.

The annual opportunity cost of the land (a) is constant over time, and hence is shown by a horizontal line, invariant with respect to the age of the forest. The interest charge against the stumpage value of the growing stock (iS) increases as the total stumpage value of the stand increases over time.

The optimum rotation is indicated where the incremental revenue curve $(\Delta S)$ intersects with the incremental cost curve $(a+i S)$ from above (at $\left.t_{m}\right)$.

The logic of this optimum is demonstrated by considering the implications of harvesting at any age other than $t_{m}$. At any point in time before $t_{m}$, the cost of holding the forest for a year is less than the value of the extra product that the forest will produce, so a positive net return will be earned by holding the forest for another year (at least). At any point beyond $t_{m}$, the annual cost of holding the forest exceeds the value it will add in a year, so a net loss will be incurred annually in holding the forest.

The cumulated cost and cumulated value curves in Figure 1-B are analogous to the total cost and total revenue curves with respect to output in conventional firm theory. The difference between cumulated costs and cumulated value will be greatest where the two curves are parallel, again at $t_{m}$.

Figure 1-C depicts the relationship between net value and stand age, which is represented by the difference between cumulated cost and cumulated value in Figure 1-B. The net value reaches a maximum where the slope of the curve is zero - at $t_{m}$ - which is, of course, the point at which the difference between cumulated cost and cumulated value is greatest.

We have here a very straight-forward solution to the problem of the optimum rotation. It can be described as that point in the age of the timber stand where the annual incremental value added is coincidental with incremental costs. In terms of the abbreviations used above, the optimum rotation occurs where

$$
\Delta \mathbf{S}=\mathbf{a}+\mathrm{is}
$$

But while this provides a simple illustration of the required solution, it unfortunately does not enable, as it stands, a determinate solution to the 

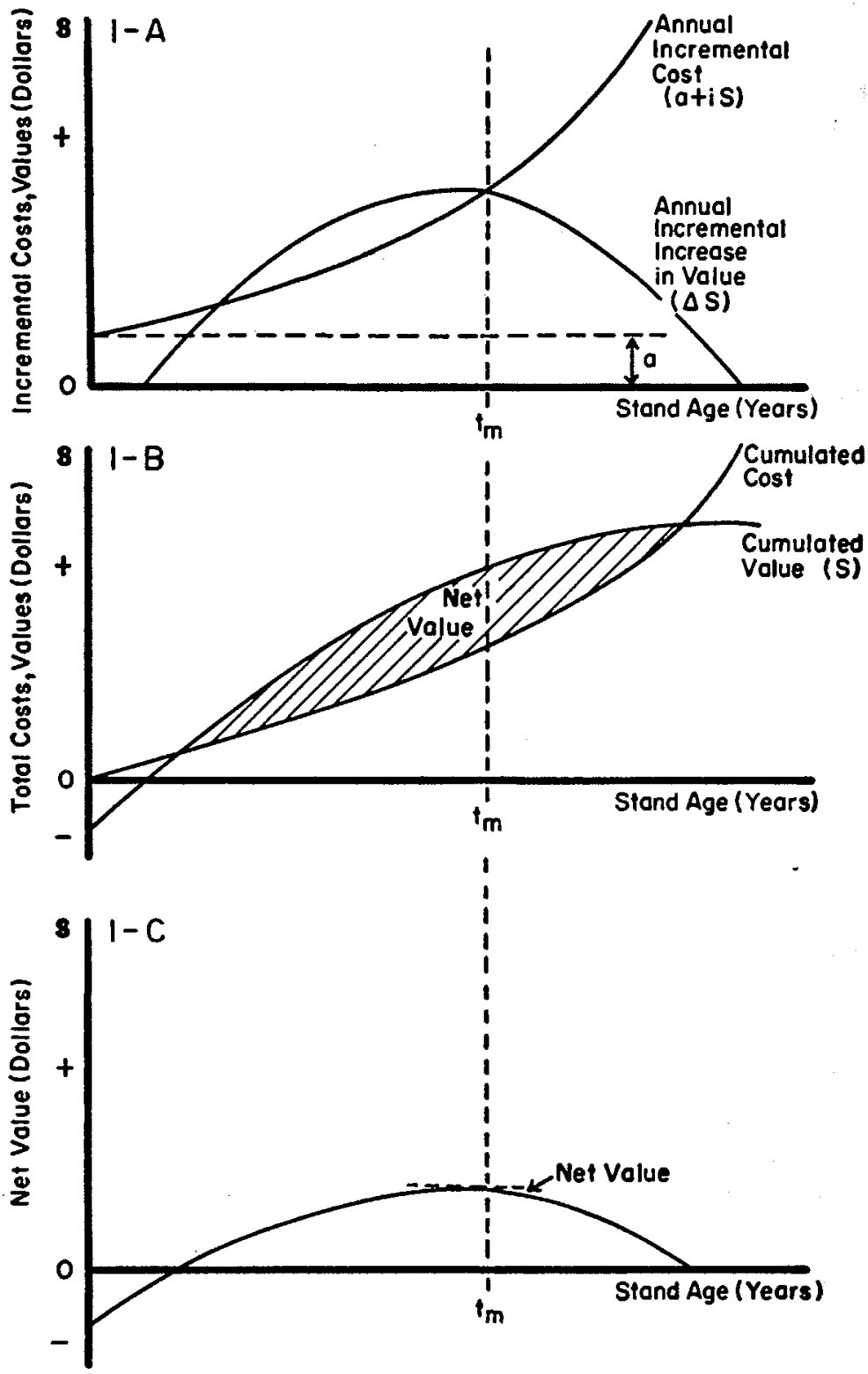

FIGURE 1: Determination of the optimum rotation. 
problem. This is because the land charge (a) can itself be determined only when the highest use of the land is known, which, if the highest use of the land is in growing timber, requires knowledge of the optimum rotation. Thus, while the land rent (a) is one of the determinants of the optimum rotation, it (a) cannot itself be determined until the optimum rotation is known.

The Land Cost and the Faustmann Formula

We are thus dealing simultaneously with two unknowns: the optimum rotation $\left(t_{m}\right)$ and the annual land cost (a). The mathematical solution, therefore, requires two equations. We already have Equation (1): the second equation is derived from an expression of the land cost (a) as a function of time.

The Faustmann formula is designed to calculate the present value of a tract of bare forest land, from which an infinite series of harvests of a value $S$ are expected at the end of each rotation period $\left(t_{m}\right)$. This present value is referred to as the "site (or soil) expectation value" (Bodenerwartungswerte in the German literature), and in its simplest form is the present value of the series.

$$
E=\frac{S}{(1+i)^{t_{m}}}+\frac{S}{(1+i)^{2 t_{m}}}+\frac{S}{(1+i)^{3 t_{m}}}+\ldots+\frac{S}{(1+i)^{2 t_{m}}}
$$

which reduces to

$$
E=\frac{S}{(1+i)^{t_{m-1}}}
$$

This site expectation value $(E)$ is the maximum amount an investor can afford to pay for the bare land. It should be noted that the formula involves the rotation period as an independent variable. The formula implies sustained periodic equal harvests, the first harvest to occur $t_{m}$ years from the present.

The site expectation value $(E)$, then, is the capitalized value of the expected future net returns from the land, valued when the land is bare at the beginning of the first rotation. It is the opportunity cost of holding a standing forest, since the alternative to holding standing timber is to harvest it, thereby reducing the value of the property to $E$.

Equation (2) therefore provides us with an expression for the opportunity cost of holding the land under the present crop of trees. But for the purposes of determining the optimum rotation we require the annual opportunity cost (a) of using the land. The annual equivalent of $\mathrm{E}$ is therefore required.

The conversion of a capital sum (E) into its annual equivalent (a) given an interest rate (i), is simply

$$
a=i(E)
$$

and this (a) is precisely the annual opportunity cost of holding the land under trees, referred to in Equation (1).

Equation (2) can now be expressed in terms of the annual cost or value of the land by substituting for $E$, thus,

$$
a=\frac{i S}{(1+i)^{t_{m}-1}}
$$

which is the Faustmann formula expressed in terms of the annual equivalent of the bare land value. 


\section{Determination of The Optimum Rotation}

Equation (4) gives the annual land cost, but is expressed in terms of the stumpage value at the optimum rotation (S). We know from Equation (1), however, that the optimum rotation is determined by the intersection of incremental revenue and incremental costs.

We now have two equations - Equations (1) and (4) - and two unknowns, viz. the land charge (a) and the rotation length $\left(t_{m}\right)$. The remaining terms are known variables. The interest rate is the required rate of return for the investor. The stumpage value $(S)$ and its rate of change $\Delta S$ are obtainable from mensurational statistics relating to the volume and quality of timber yields ("yield tables") and market prices."

Substituting the expression for the land value (a) from Equation (4) in Equation (1), we have

$$
\Delta S=\operatorname{iS}\left\{1+\frac{1}{(1+\mathrm{i})^{\mathrm{t} m-1}}\right\}
$$

which can be most readily solved in the form

$$
t_{m}=\frac{\log \Delta S-\log (\Delta S-i S)}{\log (1+i)}
$$

Solution of this equation will yield the optimum economic rotation, which will, by definition, give the highest possible value of $\mathbf{E}$ and hence also to the highest possible value for a. In other words, the optimum rotation maximizes the return to the fixed factor, land.

\section{A Practical Simplification}

The preceding theoretical discussion is aimed at showing the inter-relationships of the critical variables involved in determining the optimum rotation. In view of the nature of most mensurational data however, the solution can, for practical purposes, be obtained without resort to Equation (5). The procedure can be short-cut by simply referring to a value yield table appropriate to the forest under consideration to find the rotation which yields the highest land rent value in Equation (4).

The first two columns in the accompanying table are taken from a standard yield table for Douglas fir on a typical site (McArdle and Meyer, 1930). ${ }^{6}$

For want of more realistic illustrative data, it has been assumed, in the third column, that all wood has a stumpage value of 10 cents per cubic foot regardless of age. ${ }^{7}$ The fourth column is the ten-year increment in value divided by 10 to show the average annual incremental change between each age class. In the right-hand column, an interest rate of 7 percent has been assumed which, multiplied by the stumpage value at each age, gives annual capital cost of holding the timber. Given this information, Equation (4) can be solved for a variety of ages to determine (with simple straight-line interpolation) that the maximum land rent would be generated under a rotation age of 56 years. At this point $a=\$ .387$, and hence the present worth (E) of an acre of bare land under this optimum rotation is $\$ .387 \div .07$ or $\$ 5.53$. This solution, in terms of the variables discussed earlier, is illustrated in Figure 2. 
Incremental Costs and Value for a Typical ACre of Douglas Fir

\begin{tabular}{|c|c|c|c|c|}
\hline $\begin{array}{c}\begin{array}{c}\text { Age } \\
\text { (years) }\end{array} \\
\text { (a) }\end{array}$ & 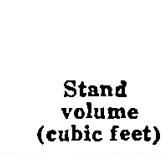 & $\begin{array}{l}\text { Stumpage } \\
\text { value (S) } \\
\text { (dollars) }\end{array}$ & $\begin{array}{c}\text { Annual } \\
\text { incremental } \\
\text { change in } \\
\text { stumpage } \\
\text { value }(\Delta \mathrm{S} \text { ) } \\
\text { (dollarg) }\end{array}$ & $\begin{array}{c}\text { Annual } \\
\text { interest } \\
\text { on attumparo } \\
\text { valuo (iS) } \\
\text { (dollars)** }\end{array}$ \\
\hline 30 & 0 & 0 & 1 & 0 \\
\hline 40 & 430 & 43 & $\begin{array}{r}4.3 \\
10.0\end{array}$ & 3.01 \\
\hline 50 & 1,430 & 143 & 160 & 10.00 \\
\hline 60 & 3,030 & 303 & 19.4 & 21.20 \\
\hline 70 & 4,970 & 497 & 15.3 & 34.79 \\
\hline 80 & 6,500 & 650 & 15.5 & 45.50 \\
\hline 90 & 8,050 & 805 & 10.8 & 56.35 \\
\hline 100 & 9,130 & 913 & 8.9 & 63.91 \\
\hline 110 & 10,020 & 1,002 & 74 & 70.14 \\
\hline 120 & 10,760 & 1,076 & & 75.32 \\
\hline
\end{tabular}

Where $\mathrm{i}=7 \%$

\section{Some Supplementary Observations}

With this information, it is possible also to examine the implications of adopting rotations other than the optimum. Calculating the site expectation value (E) as outlined above for the full range of ages, the relationship between present worth of the bare land and the rotation length selected can be derived. This is illustrated in Figure 3. The cost of selecting any rotation other than the optimum of 56 years is represented by the difference between $\$ 5.53$ and the site expectation value under the selected rotation. For example, the popular criterion of selecting the rotation to yield the highest average annual growth in wood volume indicates, in this case, a rotation of 103 years. Under this rotation the land value (a) is reduced to $\$ .061$ and the site expectation value to $\$ 0.88$. The use of the maximumvolume growth criterion rather than the maximum-value criterion thus reduces the value of forest land from $\$ 5.53$ to $\$ .88$ per acre.

A further comment on the significance of the land rent (a) is in order, since its relevance has been the subject of considerable debate in the literature. We can dismiss straightaway the arguments that land rent should be ignored if no non-forestry uses of the land are to be considered: enough has been said already to emphasize that the relevant alternative in such cases is to harvest and begin a new crop. But several forest economists, while re- 
cognising the relevance of land rent, suggest that it can usually be ignored in practice because it is insignificant. (Duerr, Fedkiw and Guttenberg 1956; Guttenberg 1953).

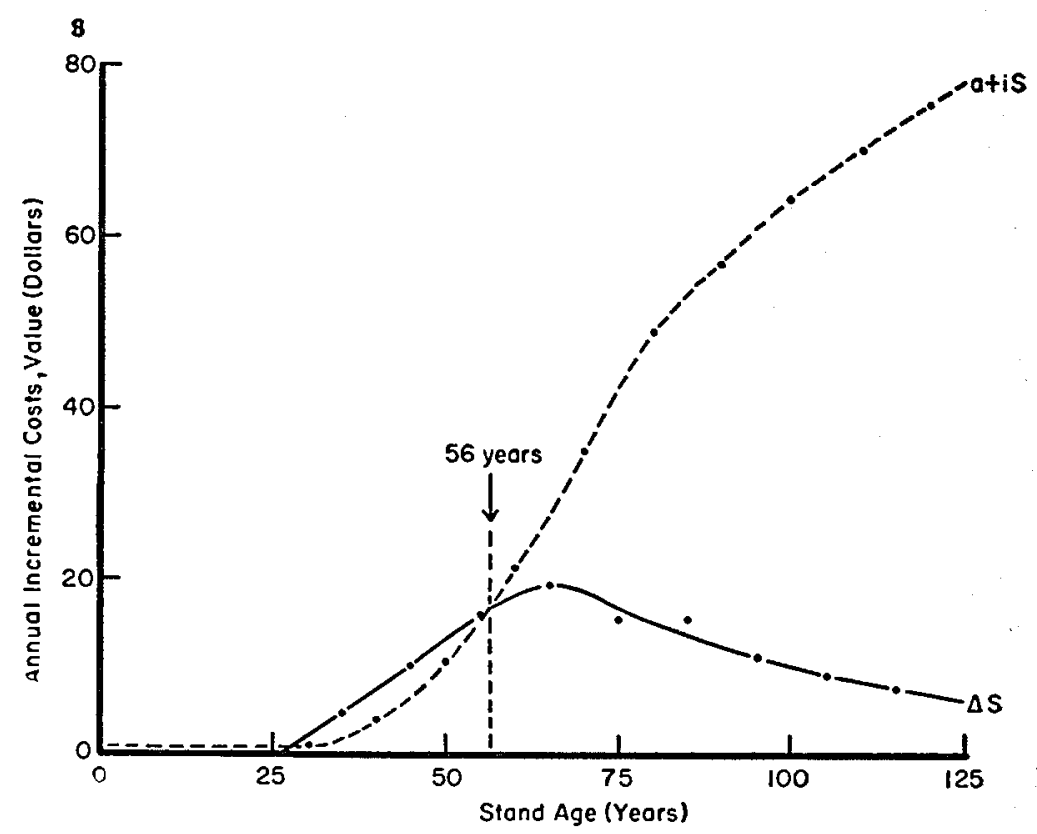

FIGURE 2: Relationship between stand age and annual incremental costs and value.

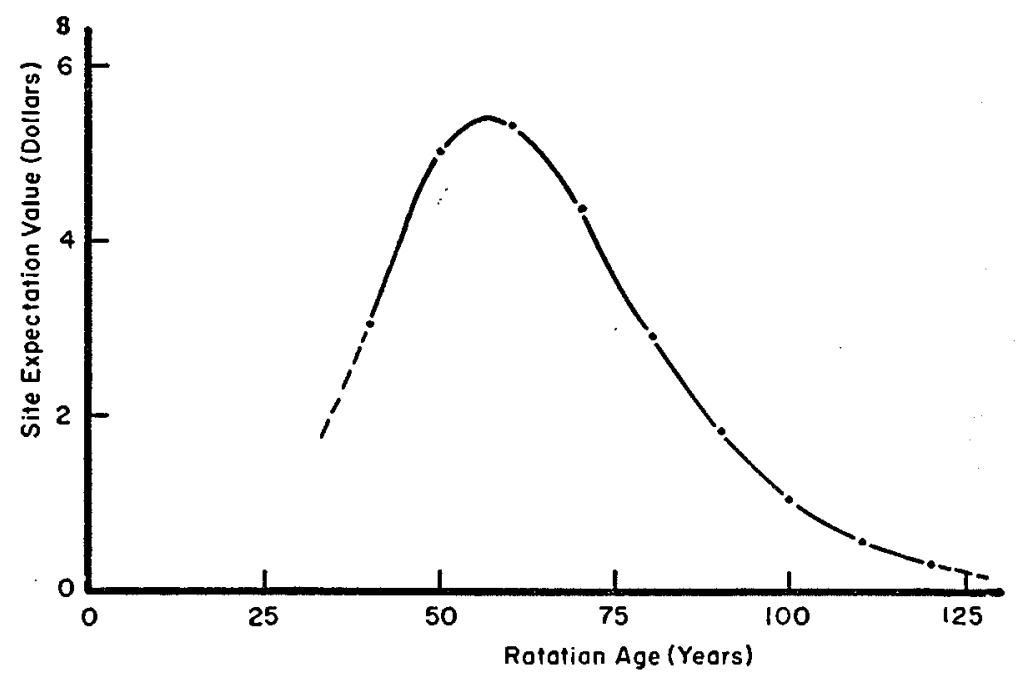

FIGURE 3: The effct of rotation age on site expectation value of an acre of Douglas fir. 
There are at least three independently sufficient reasons, however, for including the land rent variable. The first is that the magnitude of the land rent depends upon the economic circumstances of each case: while it may be small in some (or even most) cases there is every reason to expect it is significant where forest values are high. To assume it is zero involves the assumption that the land is worthless.

Secondly, the significance of the land value in affecting the calculated rotation length depends not only on its magnitude but also on the slope of the incremental cost function relative to that of the incremental value function. This can be seen in Figure 2. If, near the critical point of intersection, these two curves are nearly parallel, even a very small change in the vertical position of the incremental cost curve (that may be effected by including a small land charge) can have a significant effect on the optimum rotation. ${ }^{8}$ In other words, the importance of a given value for land rent depends upon the relative slopes of the incremental cost and value curves, and these slopes will be different for each set of conditions.

Finally, the inclusion of the land rent is useful for purposes of exposition. The objective of economic analysis in forestry is to show how the greatest return can be gained in the forest enterprise. Maximizing this return involves maximizing the return to the fixed factor. Since the fixed factor in growing forests is the land, it is helpful if the analysis defines the optimum rotation clearly in terms of maximizing the return to the land.

\section{OTHER COST IMPLICATIONS}

A particular advantage of the above formulation of the optimum rotation is that it facilitates an easy examination of the implications of various kinds of silvicultural practices and changes in the economic factors at work. A few of these will be dealt with briefly.

Changes in the interest rate. The effect of alterations in the interest rate can readily be seen with reference to Figure 4 . Reducing the interest rate by one-half from 7 percent to $3 \frac{1 / 2}{2}$ percent has two effects. First, the interest charge on the standing timber will be only half as great at any age so that the iS-curve will now be only half as high above its base (a) in any year. This effect tends to lengthen the rotation, which is what one would intuitively expect, since a lower interest rate increases the relative value of more remote returns. The second result is that the land value (a) increases, and this has the opposite effect on the rotation length. The greater "a" reflects the higher value of the land under low interest rates, since future harvests have a higher present worth.

Except in very unusual circumstances, the force of the first effect will be greater than that of the second, since, as Equation (4) suggests, a change in the interest rate will shift the interest charge on the stumpage value more than the land rent. ${ }^{9}$ The schedule representing the incremental change in stumpage value will, of course, remain unchanged. The effect, therefore, of a change in the interest rate will always be to shift the point of equality between incremental revenue and cost (Equation 1) in the opposite direction.

The interest rate selected is of critical importance in decisions involving evaluations over time. Small differences in the rate chosen for discounting returns expected in the distant future have a drastic effect on their present 
worth. It is quite incorrect to argue, as Buttrick does for example, that any arbitrary rate will do for comparative evaluations (Buttrick 1943). A lower rate will always give increased relative weight to returns receivable in the more distant future.

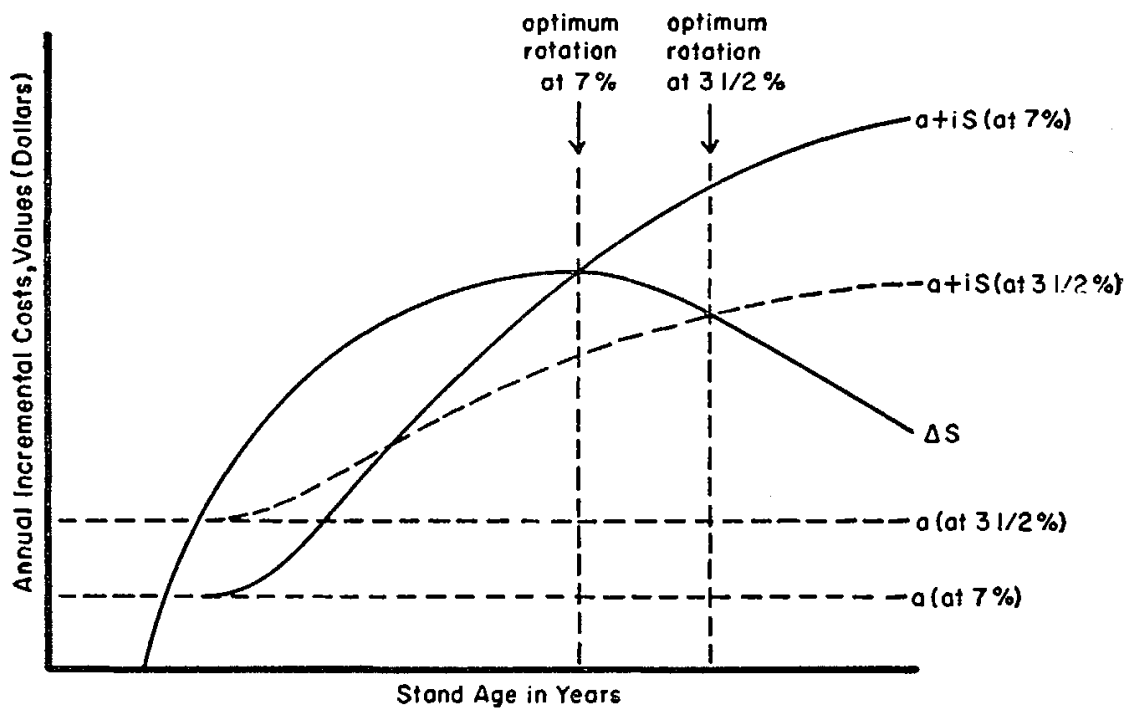

FIGURE 4: The effect on the optimum rotation of a change in the interest rate.

The effect of differences in the interest rate may have important implications for public forest policy for another reason. It has frequently been argued (though the literature is by no means conclusive) that private entrepreneurs in a competitive market do not give sufficient weight to future returns to best serve society's interest (for example, Marglin 1963, Feldstein 1964). This implies a social rate of time preference lower than the interest rate thrown up by the private market. No attempt will be made here to assess this argument, but, if it is valid, it suggests a justification of regulations aimed at inducing private forest owners to adopt a longer rotation than they otherwise would in pursuit of maximum private profit.

Planting costs. Where a succession of crops is planned, a regeneration cost can be dealt with as a cost of logging - in which case it can be deducted in calculating the stumpage value - or as a cost incurred at the beginning of the rotation. As long as harvesting and planting occur in the same year, the results will be the same. If a planting cost is regarded as occurring at the begining of the rotation, it is necessary to subtract, from the value of the final harvest, an amount equal to the planting cost (P) cumulated at the required interest rate over the length of the rotation (i.e. $P(1+i)^{t_{m}}$ ). Thus the expression for the land rent, which is to be maximized, becomes

$$
=\frac{i\left[S-P(1+i)^{t_{m}}\right]}{(1+i)^{t_{m}-1}}
$$


If regarded as a cost of logging, and hence affecting the value of the rotation just ending, the cost of planting can be subtracted from the stumpage value of the timber, which will give the same result.

In any case, a planting cost reduces the net value of the harvests and this is the clue to its effect on the optimum rotation. The incremental revenue curve $(\Delta S)$ will not change (see Figure 2) because it represents the change in stumpage values, and only the total value will be lower by a fixed amount. But the interest cost (iS) will be lower, since the net value of the harvest (S) at any time is less by the amount of the planting cost. Thus the incremental cost curve $(a+i S)$ will have a more gentle slope, and intersect the incremental revenue curve $(\Delta S)$ at a point further to the right. Moreover the presence of this further cost will reduce the value of the land a, and this will cause the intersection point to occur further to the right also. Both these effects, then, will lengthen the optimum rotation. ${ }^{10}$

Fixed annual costs. A fixed annual administrative or maintenance cost reduces the value of the land by the present capitalized value of an infinite series of future annual charges (c), which is simply $\frac{c}{i}$. But the optimum rotation remains unchanged, since the annual administrative cost must be subtracted from both sides of Equation (1). Thus the incremental cost and revenue curves in Figure 1-A shift downward by the same amount. The incremental cost curve $(\mathrm{a}+\mathrm{iS})$ shifts downward throughout its length by the amount of the annual expense which must now be subtracted from the gross return to the land to get the new net annual return (a). The incremental return $(\Delta S)$ is similarly reduced by the amount of the additional cost so the rotation is unaffected."

Thinning. Intermediate thinnings during the course of the rotation are of two types, which for convenience might be designated cultural thinnings and commercial thinnings. Cultural thinnings are those which involve a current loss, since the sale (if any) of the cut trees fails to cover the cost of the operation. The purpose of such operations is to concentrate growth on the remaining trees, thus producing timber of large size and higher quality. Cultural thinnings may or may not increase the volume of wood produced, but they will be desirable whenever the increased value of the final harvest more than covers the cost of the thinning.

Such thinnings will be worthwhile whenever the cost (T) of the thinning in a given year ( $j$ ) is less than the resulting increase in stumpage value of the final harvest discounted from the time of harvest ( $t$ ) to the year of thinning. Thus thinning will be advantageous whenever

$$
T_{j}<\frac{S_{t}^{\prime}-S_{t}}{(1+i)^{t-j}}
$$

where $S_{t}^{\prime}$ is the higher stumpage value expected as a result of the thinning.

The effect of such a thinning on the optimum rotation is illustrated in Figure 5. The thinning will increase the rate of growth in value $(\Delta S)$ from the time of thinning (and thereby tend to postpone the culmination of the 
growth rate). The effect of this upward shift in the incremental revenue curve will be to lengthen the optimum rotation. On the other hand, the incremental cost curve has been shifted downward because the interest charge now applies to a reduced total volume of wood capital. If the slope of the incremental cost curve remained the same, this would tend to extend the rotation also. But the result of the thinning is to cause the value of the crop to grow faster, yielding a higher value at harvest age, so the new incremental cost curve must overtake the original one. In addition, the increased value of the forest enterprise as a result of the profitable thinning will produce a higher land value (a) shifting the incremental cost curve further upward by this constant amount throughout its length. The overall effect of these opposing influences on the rotation length will vary, giving a rotation sometimes longer and sometimes shorter than without thinning.

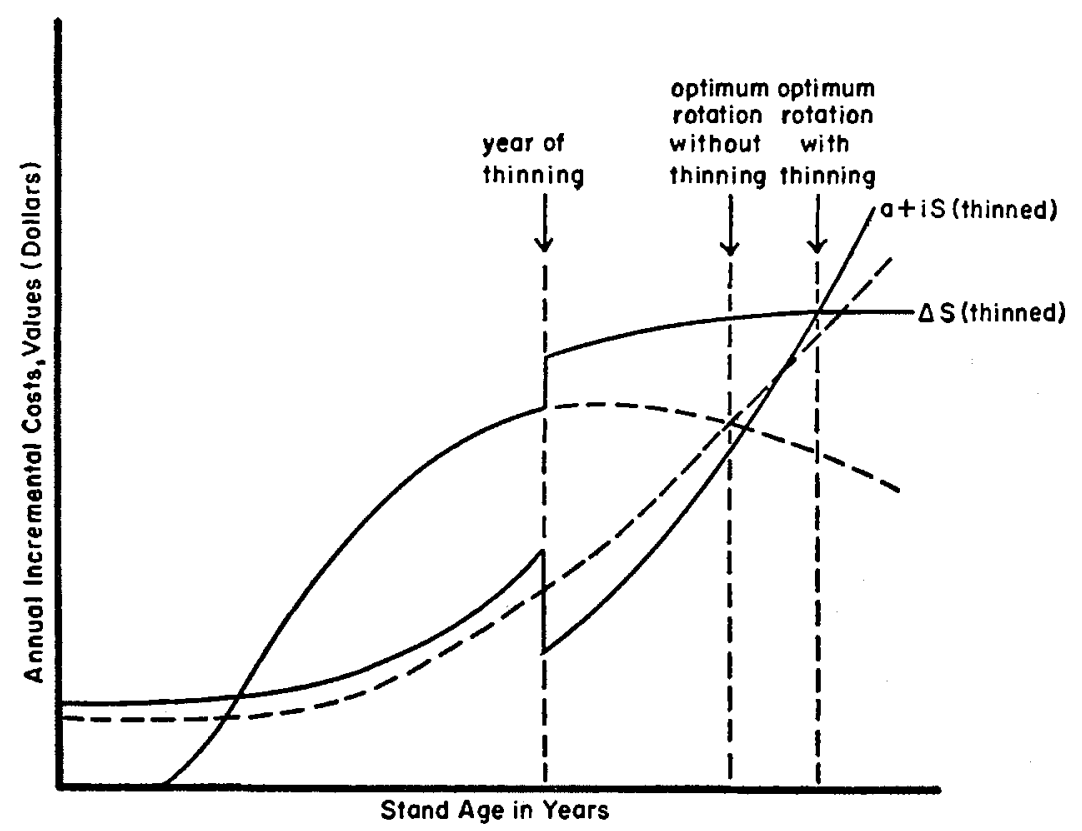

FIGURE 5: Effect on rotation of a culture thinning.

Commercial thinnings are those which will yield a current net revenue. It would be advantageous to undertake such thinnings whenever the stumpage revenue from the thinning $(R)$ is greater than any loss resulting at the final harvest $\left(S_{t}-S_{t}^{\prime}\right)$ discounted to the year of the thinning $(j) .^{12}$ This is to say, a thinning that causes a reduction in final yield should be undertaken when

$$
R_{j}>\frac{S_{t}-S_{t}^{\prime}}{(1+i)^{t-j}}
$$


The implications of such operations for the optimum rotation are shown in Figure 6. If the stand is not expected to regain the lost value before harvest, the new incremental cost curve $(a+i S)$ will lie below the original. ${ }^{13}$ In addition, if the rate of growth in value of the remaining stand is greater than it would be if unthinned, the incremental revenue curve $(\Delta S)$ will be shifted upward, and may continue to slope upward for a longer period. Both these effects will tend to lengthen the optimum rotation.

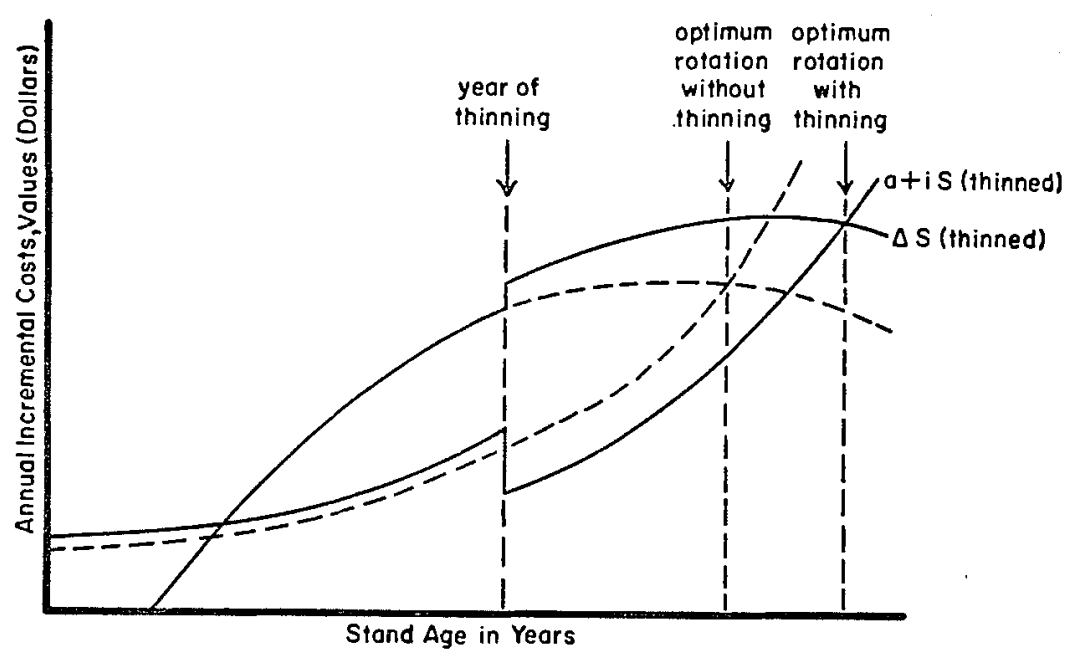

Figure 6: Effect on rotation of a commercial thinning.

Taxes. Another important public policy question that can usefully be examined with this apparatus is that concerning taxation. Let us assume, to begin with, the desirability of one of the most common principles of taxation; that taxes should not interfere with the most efficient economic use of a resource. Since we have described the optimum rotation period, an efficient tax (or a "neutral" tax) is one that will not induce a deviation from this optimum.

A simple property tax will obviously not have this desired neutrality. A percentage levy against the land and timber thereon will have the effect of adding a further percentage charge (the tax rate, $\mathrm{k}$ ) against the timber. This will tilt the incremental cost curve $(a+i S+k S)$ upward to the left, which will reduce the rotation. The amount of rent (a) that accrues to the land will be reduced as a result of the sub-optimum rotation, and the site expectation value of the site for a private owner will be reduced in proportion.

A severance tax (or royalty) in the form of a percentage charge against the value of the timber harvested would lower the incremental revenue curve, from the point of view of the private owner, in proportion to the tax rate. But the private worth of the forest capital would be reduced in proportion to the tax rate, and so the incremental costs $(a+i S)$ will be lowered con- 
comitantly. Since all incremental costs and revenues will be reduced in proportion, the indicated rotation will remain unchanged. Such a tax, therefore, will not disturb the optimum rotation.

Another tax that will avoid disturbing the optimum rotation is one levied on the annual site value. Such a tax has the same neutral effect as a fixed annual administrative cost discussed earlier. Both incremental private costs (a) and incremental net returns are reduced equally, leaving the optimum rotation unchanged. The owner cannot avoid or reduce the tax by altering the original point of highest return. Moreover, unlike either of the above taxes, returns from efforts to increase production are not reduced by such a tax, and hence it would not interfere in management decisions of any kind. This is consistent with the Ricardian precept that a tax on land rent will not in any way distort the allocation of resources.

The private net return is, of course, reduced - the site expectation value is now less by the present worth of the infinite series of future equal annual tax payments $(\mathrm{z})$ by $\frac{\mathrm{z}}{\mathrm{i}}$.

It follows that the maximum tax that the forest can sustain annually is precisely equal to the annual equivalent (a) of the site value (E). Under any tax less than a, the owner will continue to maximize his profits at the same rotation. The effect of an annual tax greater than the land rent would be to create a loss operation (the private site expectation value would be negative) and the owner would minimize his losses by allowing his title to the land to lapse.

The site value therefore sets the upper limit to the long-run taxable capacity of forest land. Any tax greater than this will, in the long run, drive private land out of forest production.

\section{ACKNOWLEDGEMENTS}

The author would like to express his thanks to Professors A. D. Scott, A. M. Moore and G. Rosenbluth for their comments on an early formulation of the problem.

\section{Literature Cited}

BENTLY, WILLIAM R., and DENNIS E. TEEGUARDEN. 1965. Financial maturity: a theoretical review. Forest Science II (1): 76-87.

BUTTRICK, P. L. 1943. Forest economics and finance. John Wiley \& Sons, New York. 484 pp.

CHAPMAN, H. H. and W. H. MEYER. 1947. Forest valuation. McGraw-Hill Book Company Inc., New York. 521 pp.

DUERR, WILLIAM A, JOHN FEDKIW and SAM GUTTENBERG. 1956. Financial maturity: a guide' to profitable timber growing. U.S. Dept. Agric. Tech. Bull. 1146. 75 pp. illus.

DUERR, WILLIAM A, 1960. Fundamentals of forestry economics. McGraw-Hill Book Company Inc., New York. 579 pp.

FAUSTMANN, MARTIN. 1849. Berechnung des Werthes, welchen Waldboden sowie noch nicht haubare Holzbestande fur die Waldwirtschaft besitzen. Allg. Forst und Jagd Zeitung 25: 441 445. 
FERNOW, BERNHARD E. 1902. Economics of forestry. Thomas Y. Crawell Co., New York (5th Ed.). 590 Pp.

FELDSTEIN, M. S. 1964. The social time preference discount rate in cost benefit analysis. Econ. J. $74(6): 360-379$.

GAFFNEY, M. MASON. 1960. Concepts of financial maturity of timber and other assets. A. E. Information Series No. 62, North Carolina State College. Raleigh. 105 pp.

GUTTENBERG, SAM. 1953. Financial maturity versus soil rent. J. For. $51(9)$ : 714-721.

HALEY, DAVID. 1966. The importance of land opportunity cost in the determination of financial rotations. J. For. 64(5): 326-329.

MARGLIN, STEPHEN A. 1963. The social rate of discount and the optimal rate of investment. Quarterly J. Econ. 77(1): 95-111.

PETRINI, SVEN. 1953. Elements of forest economics (translated by Mark L. Anderson). Oliver and Boyd, Edinburgh. 213 pp.

SMITH, J. HARRY G., and DAVID HALEY, 1964. Allowable cuts can be safely increased by use of financial rotation. Brit. Col. Lumberman. $48(7): 26-28$.

ZIVNUSKA, JOHN A. 1949. Some aspects of the economic theory of forestry. Land Econ. $25(2): 165-172$.

\section{Footnotes}

1. While this observation appears obvious enough, it renders invalid one of the most widely accepted principles in determining rotation lengths in practice-namely, that the best rotation is that which maximizes the volume (not value) of wood growth.

2. A normal profit to the logger and an allowance for risk must be considered part of the real cost of logging. (For administrative purposes, stumpage is sometimes defined gross of these items). William A. Duerr, among others, argues that the appropriate measure for evaluation is not stumpage but "conversion surplus", which is the value of the end product of the entrepreneur's production process (e.g. lumber or pulp) minus all costs of manufacture (Duerr 1960). This is incorrect, because it involves attributing to the timber profits that should properly be attributed to factors of production in the utilization processes.

3. The term "revenue" pertains here to the increase in value of the asset over time. The antithetic expressions costs and revenues help to maintain the analogy to simple firm theory.

4. The formula implies also that if the highest use of the land is in forest production, and if all prices and costs remain constant, a sustained yield policy will be the optimum management regime (as opposed to a single crop). This is so because if the first crop (i.e. the first component of the equation, $\left.\frac{S_{t}}{(1+i) t_{m}}\right)$ shows a positive present value, all successive components (crops). will show a positive present value as well, each therefore increasing $E$.

5. In keeping with familiar practice, the analysis is presented in terms of discrete changes over time (years or groups of years), although the curves in Figure 1 are drawn smooth without attempt to show step-wise changes in costs and revenues. This treatment in terms of discrete changes is not incorrect for economic analysis, though mathematicians might prefer continuous relationships (see Gaffney 1960 pp. 6-7).

6. The yield data in the table relate to the cubic foot volume of wood in trees 12 inches in diameter and larger on' a site index 120. To an increasing extent, yield tables are being compiled in more detail than those of McArdle and Meyer. Data in the form of 5-year or single-year age classes will, of course, improve the precision of the calculation, particularly if the rate of value growth changes significantly near the rotation age.

7. For the reasons discussed earlier, the value per cubic foot can be expected to increase with the age of the stand. In some cases, it is possible to calculate a sufficiently reliable predictive equation for stumpage value per acre as a function of time by using empirical observations of stumpage values near the optimum rotation age for a given forest. Such an equation could then be substituted in Equation 4 to give the land value under any rotation. 
8. I am indebted to my former student, Mr. David Haley, for his clarification of this point. (Haley 1966).

9. This can be demonstrated as follows. Except under exceptionally short rotations and low interest rates, $(1+i)^{t}-1>1$. Differentiating the two terms with respect to the interest rate, we find that the rate of change in iS with respect to $i$ is $S$, and that of the land rent is

$\frac{1}{(1+i)^{t_{-1}}}<1$, and $\frac{\text { it }(1+i)^{t-1}}{\left((1+i)^{t}-1\right)^{2}}$ is positive.

10. Sometimes the alternative to planting is to wait a few years for delayed natural regeneration. Planting is to be preferred whenever the present worth of forestry operations with planting costs is greater than the corresponding worth without these costs bur with each harvest delayed by the number of years (u) required for natural regeneration to occur. Thus planting would be preferable in sustained yield forestry whenever

$$
\frac{S-P(1+i)^{t}}{(1+i)^{t}-1}>\frac{S}{(1+i)^{t+u_{-1}}}
$$

11. Petrini, finding the Faustmann formula of ten yielded negative values for forest land, suggested, curiously, this was because administration costs were dealt with in the above manner whereas they (in part at least) were really costs of intermediate harvests (Petrini 1953). The confusion results simply from a failure to correctly identify costs. The procedure advocated here-and that implied by Faustmann-is that harvesting costs are dealt with in stumpage values, and that administrative costs are truly annual fixed costs of maintaining the property.

12. It should be obvious that any commercial thinning that will not reduce future stumpage should be undertaken.

13. The increase in the land value (a) resulting from the more profitable management regime will usually be less than the reduction in the interest charge (iS) on the timber for reasons explained in Footnote 9 (above). 